\title{
The rs878081 polymorphism of AIRE gene increases the risk of rheumatoid arthritis in a Chinese Han population: a case-control study
}

\author{
Haoyu Yang ${ }^{1 *}$, Jin Li ${ }^{3 *}$, Lifeng Jiang ${ }^{2}$, Xijia Jiang $^{1}$, Xindie Zhou ${ }^{1}$ and Nanwei Xu ${ }^{1}$ \\ ${ }^{1}$ Department of Orthopedics, The Affiliated Changzhou No.2 People's Hospital of Nanjing Medical University, \\ Changzhou, Jiangsu Province, China \\ ${ }^{2}$ Department of Orthopedic Surgery, The Second Affiliated Hospital, Zhejiang University School of Medicine, Hangzhou, China \\ ${ }^{3}$ Department of Orthopedic Surgery, The Second Affiliated Hospital of Jiaxing University, Jiaxing City, Zhejiang Province, China
}

\begin{abstract}
The autoimmune regulator (AIRE), a transcriptional regulator expressed in medullary thymic epithelial cells, plays an important role in thymocyte education and negative selection. Several citations studying the association between the rs 878081 exon polymorphism of the AIRE gene and the risk of rheumatoid arthritis (RA) in different populations have yielded conflicting findings. Thus, this case-control study involving 300 RA cases and 300 controls was aimed to identify whether such association existed in a Chinese Han population from East China. The rs878081 polymorphism of the AIRE gene was genotyped. Odds ratios (ORs) and 95\% confidence intervals (Cls) were estimated using the chi-squared test, genetic model analysis, and stratification analysis. Genetic model analysis showed significant correlations between the TT genotype and the risk of RA (OR: 1.89, 95\%Cl: $1.03-3.47$ in TT vs CC; OR: 1.84, 95\% Cl: 1.02-3.31 in TT vs CC + TC). Stratification analyses of sex, age, smoking, and alcoholism suggested that the rs 878081 polymorphism of the AIRE gene increased RA risk among non-smokers. In conclusion, rs878081 polymorphism of AIRE gene increases the risk of RA in a Chinese Han population.
\end{abstract}

Key words: AIRE; Single-nucleotide polymorphism; Rheumatoid arthritis; Case-control study

\section{Introduction}

Rheumatoid arthritis (RA), an autoimmune disease affected by multiple factors (1), could cause critical functional impairment and work-related disability despite its low prevalence $(\sim 1 \%)(1)$. No significant reduction in mortality in different RA populations worldwide has been demonstrated $(2,3)$. It has also been reported that the improvement in survival lags behind the recent advances in RA management (2). In addition, the etiology and pathogenesis of RA are still unknown (4). The combination of environmental and genetic factors plays a major regulating role in the development and progression of RA.

The autoimmune regulator (AIRE) is a transcriptional regulator expressed in thymic medullary cells (5). Experimental studies show that single nucleotide polymorphisms (SNPs) alter transcription of the AIRE gene, which is located in the $21 \mathrm{q} 22.3$ region, $\sim 12.5 \mathrm{~kb}$ long, encoding a 545 amino acid protein of $58 \mathrm{kDa}$ by 14 exonial sequences (6). SNPs thereby provide a less efficient negative selection, and improve the survival of autoimmune T-cells and the susceptibility to autoimmune diseases (7-9). A genomewide association study in a Japanese population identified two SNPs (rs2075876 and rs760426) in the AIRE gene significantly associated with RA risk (10). Moreover, several citations (11-13) studying the association between the AIRE gene rs878081 polymorphism and RA risk in different populations brought conflicting findings. According to dbSNP database, rs878081 is located in the exon region of the AIRE gene. The minor allele frequency (MAF) of T allele in rs878081 polymorphism was 0.133 according to the 1000 Genomes Browser (https://www.ncbi.nlm.nih.gov/ variation/tools/1000genomes/). The MAFs of T allele in rs878081 polymorphism in the cases were 0.196, 0.074, and 0.290 in a Spanish population (11), a Chinese population from Hebei province (12), and a Chinese population from Shanxi province (13), respectively. To date, there is no association study of this SNP among the Chinese Han population in East China. Thus, this case-control study aimed to investigate whether rs878081 polymorphism of the AIRE

Correspondence: Xijia Jiang: <jiangxijia_123@126.com> | Xindie Zhou: <xindiezhou@163.com>

*These authors contributed equally to this study.

Received July 8, 2018 | Accepted September 18, 2018 
gene was associated with the risk and development of RA in a Chinese Han population from Jiangsu province (East China).

\section{Material and Methods}

\section{Patients and methods}

In this hospital-based case-control design, 300 hospitalized RA patients (79 males and 221 females) were recruited from the Affiliated Changzhou No.2 People's Hospital of Nanjing Medical University or the Second Affiliated Hospital of Jiaxing University between January 2014 and October 2017. They were diagnosed following the criteria of the American College of Rheumatology/European League against Rheumatism Collaborative Initiative for RA (14). All patients were clinically evaluated by two rheumatologists. The demographic and RA data were obtained from patient data sheets. All the recruited people were Chinese Han.

Patients with other nationalities, consanguinity, other major systemic disease, collagen vascular disease, other autoimmune diseases, hepatitis $\mathrm{C}$ virus infection, or family history of autoimmune diseases were excluded. Also, 300 unrelated healthy controls (128 males and 172 females) were randomly recruited from the subjects receiving regular health examinations at either of the two hospitals during the same period.

RA activity was measured using the Disease Activity Score in 28 joints and the erythrocyte sedimentation rate (DAS28-ESR) (15), which evaluates the tenderness and swelling in 28 joints. Grades of disease activity were classified as follows: high $\geqslant 5.1$, moderate $<5.1$ and $\geqslant 3.2$, low $<3.2$ and $\geqslant 2.6$, and clinical remission $<2.6$.

Both serum and ethylene-diamine-tetra-acetic acid (EDTA) blood samples were collected from both groups for measurement of rheumatoid factor (RF), C-reactive protein (CRP), erythrocyte sedimentation rate (ESR), anticyclic citrullinated peptide (anti-CCP) antibodies, and AIRE gene polymorphism. Both RF and CRP were measured using a nephelometer (Turbox plus analyzer, Orion Diagnostica, Finland). Anti-CCP antibodies were analyzed by thirdgeneration enzyme-linked immunosorbent assay (ELISA; CCP3 lgG, Inova Quanta Lite ${ }^{T M}$, USA). The cut-off value for CRP was $\geqslant 10 \mathrm{mg} / \mathrm{L}$, for RF was $\geqslant 25 \mathrm{IU} / \mathrm{mL}$, and for antiCCP antibodies was $<20$ negative, $20-39$ weakly positive, $40-59$ moderately positive, and $\geqslant 60$ strongly positive.

A detailed questionnaire about smoking and alcoholism habits was completed for each participant by a trained interviewer. Informed consent was obtained from all participants prior to their participation. Ethical approval, which was in line with the Declaration of Helsinki standards, for the study protocol was obtained from the Ethics Committees of the two Hospitals.

\section{DNA extraction and genotyping}

Blood samples were collected using vacutainer tubes and then transferred to EDTA tubes. Genomic DNA was isolated from whole blood using a QIAamp DNA blood mini kit (Qiagen, Germany). Genotyping was performed by matrix-assisted laser desorption/ionization time-of-flight mass spectrometry (MALDI-TOF MS) as previously described (16). SNP was genotyped by the MassARRAY system (Sequenom, USA) and by MALDI-TOF MS, which was performed without knowing patient status (case vs control) to ensure the quality of genotyping.

\section{Genotype and gene expression correlation analysis}

Genotype data of the AIRE gene rs878081 polymorphism were available online from the International HapMap Project. The mRNA expression data were available online from Genotype-Tissue Expression Portal (https://www. gtexportal.org/home/) (17).

\section{mRNA extraction and real-time PCR}

According to the manufacturer's protocol, mRNAs were extracted from blood samples using TRIzol reagent (Invitrogen; Thermo Fisher Scientific, Inc, USA). cDNA was synthesized using a PrimeScript RT Reagent kit (Takara Biotechnology Co., Ltd., China) at $37^{\circ} \mathrm{C}$ for $15 \mathrm{~min}, 85^{\circ} \mathrm{C}$ for $5 \mathrm{~s}$, and determined at $4^{\circ} \mathrm{C}$, while qPCR was conducted using a SYBR Premix Ex Taq kit (Takara Biotechnology Co., Ltd.) on a Bio-Rad iQ5 Real-Time PCR system (BioRad Laboratories, Inc., USA). The following thermocycling conditions were used for the PCR: $50^{\circ} \mathrm{C}$ for $2 \mathrm{~min}, 95^{\circ} \mathrm{C}$ for $10 \mathrm{~min}$, followed by 40 cycles of $95^{\circ} \mathrm{C}$ for $15 \mathrm{~s}$ and $60^{\circ} \mathrm{C}$ for $1 \mathrm{~min}$. The primer sequences for amplification were $5^{\prime}-\mathrm{GAG}$ AGTGCTGAGAAGGACA-3' (forward) and 5'-GTTTAATTTC CAGGCACATGA-3' (reverse). The relative expression was calculated using the $2^{-\Delta \Delta \mathrm{Cq}}$ method, with glyceraldehyde3-phosphate dehydrogenase (GAPDH) used as the internal control.

\section{Statistical analysis}

Demographic characteristics and rs878081 genotypes of the AIRE gene were evaluated using a chi-squared test $\left(\chi^{2}\right)$ (for categorical variables) or Student's t-test (for continuous variables). The associations between the rs878081 T/C genotypes and the risk of RA were estimated by calculating odds ratios (ORs) and 95\% confidence intervals (Cls) using logistic regression analysis; crude ORs and adjusted ORs were used in case of adjustment for age and sex. The Hardy-Weinberg equilibrium (HWE) was assessed by a goodness-of-fit $\chi^{2}$ test to compare the observed genotype frequencies with the expected frequencies in controls. This study was powered to detect the effect of rs878081 polymorphism of the AIRE gene on RA susceptibility at $P<0.05$ (18). All statistical analyses were performed on SAS software 9.1.3 (SAS Institute, USA).

\section{Results}

\section{Characteristics of the study population}

The characteristics of the study population are summarized in Table 1, including DAS28 grades and morning stiffness. The case and control groups were well-matched 
Table 1. Demographics and baseline characteristics of rheumatoid arthritis patients.

\begin{tabular}{|c|c|c|}
\hline & Patient $(n=300)$ & Control $(n=300)$ \\
\hline Age, years (mean $\pm S D)$ & $54.5 \pm 15.48$ & $53.84 \pm 10.48$ \\
\hline Gender (male / female) & $134 / 166$ & $146 / 154$ \\
\hline Smoking (yes / no) & $120 / 180$ & $121 / 179$ \\
\hline Alcohol (yes / no) & $87 / 213$ & $86 / 214$ \\
\hline Disease duration, years (mean $\pm \mathrm{SD}$ ) & $9.10 \pm 9.35$ & \\
\hline Disease onset (age; mean $\pm \mathrm{SD}$ ) & $45.46 \pm 12.58$ & \\
\hline Family history (yes / no) & $76 / 224$ & \\
\hline DAS28 (median \pm SD) & $4.35 \pm 1.61$ & \\
\hline \multicolumn{3}{|l|}{ DAS28 grade $(n, \%)$} \\
\hline High activity & $25(8.3 \%)$ & \\
\hline Moderate & $110(36.7 \%)$ & \\
\hline Low & $132(44.0 \%)$ & \\
\hline Remission & $33(11.0 \%)$ & \\
\hline $\mathrm{N}$ of tender joints (mean $\pm \mathrm{SD}$ ) & $8.68 \pm 5.84$ & \\
\hline $\mathrm{N}$ of swollen joints (mean $\pm \mathrm{SD}$ ) & $10.26 \pm 5.53$ & \\
\hline Deformity (n) & $113 / 187$ & \\
\hline \multicolumn{3}{|l|}{ Morning stiffness (n, \%) } \\
\hline None & $60(20.0 \%)$ & \\
\hline$\leqslant 1.0 \mathrm{~h}$ & $169(56.3 \%)$ & \\
\hline$>1.0 \mathrm{~h}$ & $71(23.7 \%)$ & \\
\hline Positive / Negative Rheumatoid factor ( $\mathrm{n}$ ) & $241 / 59$ & \\
\hline Positive / Negative CRP (n) & $185 / 115$ & \\
\hline $\mathrm{ESR}($ median $\pm \mathrm{SD})$ & $33.84 \pm 21.85$ & \\
\hline Positive / Negative Anti-CCP (n) & $165 / 135$ & \\
\hline
\end{tabular}

DAS28: disease activity score in 28 joints; CRP: C-reactive protein; ESR: erythrocyte sedimentation rate; CCP: cyclic citrullinated peptide.

in terms of gender (male proportion= $44.67 \%$ vs $48.67 \%$ ) and age (mean age $=54.50$ vs 53.84 years). No significant differences between groups were found in smoking or alcoholism.

\section{Association between rs878081 polymorphism and RA risk}

Genotype distributions of the rs878081 polymorphism of the AIRE gene among all subjects are reported in Table 2. The rate of genotyping was $>98 \%$, and the test polymorphism of the study population was under HWE $(P>0.05)$. Logistic regression analyses revealed the rs878081 polymorphism increased the risk of RA in two genetic models (OR: $1.89,95 \% \mathrm{Cl}: 1.03-3.47$ in TT vs CC, $\mathrm{P}=0.039$ and OR: $1.84,95 \% \mathrm{Cl}: 1.02-3.31$ in TT vs $\mathrm{CC}+\mathrm{TC}, \mathrm{P}=0.043$; Table 2). The effects of the SNP on $\mathrm{RA}$ risk were further evaluated according to age, gender, smoking, and drinking. The increased RA risk conferred by rs 878081 was more significant in females and nonsmoking patients (Table 3). However, no significant association was found between rs878081 genotypes and clinical or biochemical characteristics except for tender joints $(P=0.020$, Table 4). Furthermore, no significant difference in demographic or laboratory data was found between CC + CT and TT genotypes (Table 5) or between CC and CT + TT genotypes (Table 6).

\section{Association between rs 878081 polymorphism and RA population}

According to dbSNP database and Genotype-Tissue Expression Portal (17), the TT genotype decreased the AIRE mRNA levels compared to CC genotype in the adipose-subcutaneous (Figure 1). A significant difference was found in the expression levels for rs878081 polymorphism with the expression quantitative trait loci (eQTL) analysis $(P<0.01)$.

Similar results were observed in the patients' blood samples. A statistically significant difference in the mean levels of expression of the rs878081 alleles was found $(P=0.018)$. The transcription of AIRE was decreased by the $\mathrm{T}$ allele compared with the $\mathrm{C}$ allele (Figure 2).

\section{Discussion}

The association between the rs878081 polymorphism of the AIRE gene and the risk of RA was investigated in a Chinese population, which showed that the polymorphism conferred susceptibility to RA. 
Table 2. Distribution of autoimmune regulator (AIRE) gene rs878081 alleles and genotypes in rheumatoid arthritis patients and healthy controls.

\begin{tabular}{|c|c|c|c|c|}
\hline AIRE gene polymorphism & $\begin{array}{c}\text { Patients }(n=298) \\
(n, \%)\end{array}$ & $\begin{array}{c}\text { Control }(n=299) \\
(n, \%)\end{array}$ & OR $(95 \% \mathrm{Cl})$ & $P$ value \\
\hline \multicolumn{5}{|l|}{ Allele } \\
\hline $\mathrm{C}$ & $421(70.6 \%)$ & $450(75.3 \%)$ & Reference & \\
\hline $\mathrm{T}$ & $175(29.4 \%)$ & $148(24.7 \%)$ & 1.26; (0.98-1.63) & 0.073 \\
\hline \multicolumn{5}{|l|}{ Genotype } \\
\hline $\mathrm{CC}$ & $156(52.3 \%)$ & $170(56.9 \%)$ & Reference & \\
\hline CT & $109(36.6 \%)$ & $110(36.8 \%)$ & 1.08; (0.77-1.52) & 0.660 \\
\hline TT & $33(11.1 \%)$ & $19(6.3 \%)$ & 1.89; (1.03-3.47) & 0.039 \\
\hline $\mathrm{CC}+\mathrm{CT}$ vs TT & 265 / $33(88.9 / 11.1)$ & $280 / 19(93.6$ / 6.4) & $1.84 ;(1.02-3.31)$ & 0.043 \\
\hline $\mathrm{TT}+\mathrm{CT}$ vs $\mathrm{CC}$ & $142 / 156(47.7 / 52.3)$ & $129 / 170(43.1 / 56.9)$ & $1.19 ;(0.86-1.66)$ & 0.269 \\
\hline HWE & & 0.831 & & \\
\hline
\end{tabular}

HWE: Hardy Weinberg equation.

Table 3. Stratified analyses between $r \$ 878081$ polymorphism and the risk of rheumatoid arthritis stratified by factors.

\begin{tabular}{|c|c|c|c|c|c|c|c|}
\hline \multirow[t]{2}{*}{ Variable } & \multicolumn{3}{|c|}{ Rs878081 (case/control) } & \multicolumn{4}{|c|}{ OR $(95 \% \mathrm{Cl}) ; \mathrm{P}$} \\
\hline & $\mathrm{CC}$ & CT & $\mathrm{TT}$ & CT vs CC & TT vs CC & $\mathrm{CT}+\mathrm{TT}$ vs $\mathrm{CC}$ & $\mathrm{TT}$ vs $\mathrm{CT}+\mathrm{CC}$ \\
\hline \multicolumn{8}{|l|}{ Sex } \\
\hline \multirow[t]{2}{*}{ Male } & $73 / 88$ & $51 / 51$ & $10 / 7$ & $\begin{array}{c}1.21 \\
(0.73-1.98)\end{array}$ & $\begin{array}{c}1.72 \\
(0.62-4.75)\end{array}$ & $\begin{array}{c}1.27 \\
(0.79-2.04)\end{array}$ & $\begin{array}{c}1.60 \\
(0.59-4.34)\end{array}$ \\
\hline & & & & 0.461 & 0.294 & 0.327 & 0.354 \\
\hline \multirow[t]{2}{*}{ Female } & $83 / 82$ & $58 / 59$ & $23 / 12$ & $\begin{array}{c}0.96 \\
(0.60-1.54)\end{array}$ & $\begin{array}{c}1.87 \\
(0.88-4.00)\end{array}$ & $\begin{array}{c}1.13 \\
(0.73-1.75)\end{array}$ & $\begin{array}{c}1.92 \\
(0.92-4.00)\end{array}$ \\
\hline & & & & 0.865 & 0.106 & 0.595 & 0.083 \\
\hline \multicolumn{8}{|l|}{ Age } \\
\hline \multirow[t]{2}{*}{$\geqslant 55$} & $80 / 84$ & $61 / 44$ & $15 / 6$ & $\begin{array}{c}1.44 \\
(0.88-2.36)\end{array}$ & $\begin{array}{c}2.59 \\
(0.96-7.01)\end{array}$ & $\begin{array}{c}0.95 \\
(0.60-1.48)\end{array}$ & $\begin{array}{c}2.27 \\
(0.85-6.02)\end{array}$ \\
\hline & & & & 0.150 & 0.061 & 0.807 & 0.100 \\
\hline \multirow[t]{2}{*}{$<55$} & $76 / 86$ & $48 / 66$ & $18 / 13$ & $\begin{array}{c}0.82 \\
(0.51-1.33)\end{array}$ & $\begin{array}{c}1.56 \\
(0.72-3.40)\end{array}$ & $\begin{array}{c}1.60 \\
(1.00-2.55)\end{array}$ & $\begin{array}{c}1.70 \\
(0.80-3.60)\end{array}$ \\
\hline & & & & 0.425 & 0.259 & 0.051 & 0.168 \\
\hline \multicolumn{8}{|l|}{ Smoking } \\
\hline \multirow[t]{2}{*}{ Yes } & $77 / 69$ & $35 / 45$ & $7 / 7$ & $\begin{array}{c}0.69 \\
(0.40-1.19)\end{array}$ & $\begin{array}{c}0.89 \\
(0.30-2.65)\end{array}$ & $\begin{array}{c}0.72 \\
(0.43-1.22)\end{array}$ & $\begin{array}{c}1.02 \\
(0.35-3.00)\end{array}$ \\
\hline & & & & 0.181 & 0.827 & 0.224 & 0.974 \\
\hline \multirow[t]{2}{*}{ No } & $79 / 101$ & $74 / 65$ & $26 / 12$ & $\begin{array}{c}1.45 \\
(0.93-2.26)\end{array}$ & $\begin{array}{c}2.76 \\
(1.31-5.81)\end{array}$ & $\begin{array}{c}1.66 \\
(1.09-2.52)\end{array}$ & $\begin{array}{c}2.35 \\
(1.15-4.82)\end{array}$ \\
\hline & & & & 0.010 & 0.007 & 0.018 & 0.020 \\
\hline \multicolumn{8}{|l|}{ Alcoholism } \\
\hline \multirow[t]{2}{*}{ Yes } & $50 / 53$ & $30 / 30$ & $7 / 3$ & $\begin{array}{c}1.06 \\
(0.56-2.00)\end{array}$ & $\begin{array}{c}2.47 \\
(0.61-10.09)\end{array}$ & $\begin{array}{c}1.19 \\
(0.65-2.18)\end{array}$ & $\begin{array}{c}2.42 \\
(0.61-9.68)\end{array}$ \\
\hline & & & & 0.858 & 0.207 & 0.578 & 0.212 \\
\hline \multirow[t]{2}{*}{ No } & $106 / 117$ & $79 / 80$ & $26 / 16$ & $\begin{array}{c}1.08 \\
(0.72-1.62)\end{array}$ & $\begin{array}{c}1.78 \\
(0.90-3.49)\end{array}$ & $\begin{array}{c}1.21 \\
(0.82-1.77)\end{array}$ & $\begin{array}{c}1.73 \\
(0.90-3.33)\end{array}$ \\
\hline & & & & 0.714 & 0.096 & 0.334 & 0.101 \\
\hline
\end{tabular}

Bold type indicates statistically significant. 
Table 4. Comparison of studied data according to autoimmune regulator (AIRE) gene genotypes in all rheumatoid arthritis (RA) cases.

\begin{tabular}{lcccc}
\hline & \multicolumn{3}{c}{ RA } & P \\
\cline { 2 - 4 } & CC $(\mathrm{n}=156)$ & $\mathrm{CT}(\mathrm{n}=109)$ & $\mathrm{TT}(\mathrm{n}=33)$ & \\
\hline Age (years; mean \pm SD) & $54.48 \pm 15.95$ & $54.93 \pm 15.48$ & $53.45 \pm 13.42$ & 0.891 \\
Males (n, \%) & $73(46.8 \%)$ & $51(46.8 \%)$ & $10(30.3 \%)$ & 0.199 \\
Females (n, \%) & $83(53.2 \%)$ & $58(53.2 \%)$ & $23(69.7 \%)$ & \\
Family history (n, \%) & $39(25.0 \%)$ & $32(29.4 \%)$ & $5(15.2 \%)$ & 0.255 \\
Onset (years; median \pm SD) & $45.47 \pm 12.72$ & $45.91 \pm 13.11$ & $43.91 \pm 10.16$ & 0.728 \\
Morning stiffness (n, \%) & & & & 0.557 \\
$\quad 0$ & $29(18.6 \%)$ & $24(22.0 \%)$ & $7(21.2 \%)$ & \\
$\quad<1$ hour & $93(59.6 \%)$ & $59(54.1 \%)$ & $15(45.5 \%)$ & \\
$\quad 31$ hour & $34(21.8 \%)$ & $26(23.9 \%)$ & $11(33.3 \%)$ & 0.278 \\
Deformities (n, \%) & $57(36.5 \%)$ & $46(42.2 \%)$ & $9(27.3 \%)$ & 0.628 \\
ESR (median \pm SD) & $34.15 \pm 21.92$ & $32.70 \pm 21.52$ & $36.82 \pm 23.20$ & 0.504 \\
Positive CRP (n, \%) & $91(58.3 \%)$ & $70(64.2 \%)$ & $22(66.7 \%)$ & 0.862 \\
Positive RF (n, \%) & $127(81.4 \%)$ & $86(78.9 \%)$ & $27(81.8 \%)$ & 0.431 \\
Positive anti-CCP (n, \%) & $88(56.45 \%)$ & $56(51.4 \%)$ & $21(63.6 \%)$ & 0.020 \\
Tender joints (median \pm SD) & $9.22 \pm 5.99$ & $7.48 \pm 5.49$ & $10.06 \pm 5.83$ & 0.727 \\
Swollen joints (median \pm SD) & $10.42 \pm 5.66$ & $10.19 \pm 5.52$ & $9.58 \pm 5.15$ & 0.946 \\
DAS (median \pm SD) & $4.33 \pm 1.57$ & $4.39 \pm 1.70$ & $4.32 \pm 1.53$ & \\
\hline
\end{tabular}

ESR: erythrocyte sedimentation rate; CRP: C-reactive protein; RF: rheumatoid factor; CCP: cyclic citrullinated peptide; DAS: disease activity score in 28 joints. Statistical analyses were carried out with one-way ANOVA and the chi-squared test.

Table 5. Comparison of studied data according to autoimmune regulator (AIRE) genotypes in all rheumatoid arthritis (RA) cases.

\begin{tabular}{|c|c|c|c|}
\hline & \multicolumn{2}{|c|}{$\mathrm{RA}(\mathrm{n}=300)$} & \multirow[t]{2}{*}{$\mathrm{P}$} \\
\hline & $C C+C T(n=265)$ & $\mathrm{TT}(\mathrm{n}=33)$ & \\
\hline Age (years, mean $\pm S D$ ) & $54.66 \pm 15.73$ & $53.45 \pm 13.42$ & 0.673 \\
\hline Males (n, \%) & $124(46.8 \%)$ & $10(30.3 \%)$ & 0.073 \\
\hline Females $(n, \%)$ & $141(53.2 \%)$ & $23(69.7 \%)$ & \\
\hline Family history $(\mathrm{n}, \%)$ & $71(26.8 \%)$ & $5(15.2 \%)$ & 0.148 \\
\hline Onset (years, median $\pm S D$ ) & $45.65 \pm 12.86$ & $43.91 \pm 10.16$ & 0.455 \\
\hline Morning stiffness $(n, \%)$ & & & 0.338 \\
\hline 0 & $53(20.0 \%)$ & $7(21.2 \%)$ & \\
\hline$<1$ hour & $152(57.4 \%)$ & $15(45.5 \%)$ & \\
\hline$>1$ hour & $60(22.6 \%)$ & $11(33.3 \%)$ & \\
\hline Deformities (n, \%) & $103(38.9 \%)$ & $9(27.3 \%)$ & 0.195 \\
\hline $\mathrm{ESR}($ median $\pm \mathrm{SD})$ & $33.55 \pm 21.73$ & $36.82 \pm 23.20$ & 0.419 \\
\hline Positive CRP (n, \%) & $161(60.8 \%)$ & $22(66.7 \%)$ & 0.511 \\
\hline Positive RF (n, \%) & $213(80.4 \%)$ & $27(81.8 \%)$ & 0.844 \\
\hline Tender joints (median \pm SD) & $8.51 \pm 5.84$ & $10.06 \pm 5.83$ & 0.150 \\
\hline Swollen joints (median \pm SD) & $10.32 \pm 5.59$ & $9.58 \pm 5.15$ & 0.465 \\
\hline DAS (median $\pm S D)$ & $4.36 \pm 1.62$ & $4.32 \pm 1.53$ & 0.905 \\
\hline
\end{tabular}

ESR: erythrocyte sedimentation rate; CRP: C-reactive protein; RF: rheumatoid factor; DAS: disease activity score in 28 joints. Statistical analyses were carried out with the $t$-test and chi-squared test. 
Table 6. Comparison of studied data according to autoimmune regulator (AIRE) genotypes in all rheumatoid arthritis (RA) cases.

\begin{tabular}{lrrr}
\hline & \multicolumn{2}{c}{ RA $(\mathrm{n}=300)$} & $\mathrm{P}$ \\
\cline { 2 - 4 } & $\mathrm{CC}(\mathrm{n}=156)$ & $\mathrm{CT}+\mathrm{TT}(\mathrm{n}=142)$ & 0.954 \\
\hline Age (years, mean \pm SD) & $54.48 \pm 15.95$ & $54.58 \pm 15.00$ & 0.506 \\
Males $(\mathrm{n}, \%)$ & $73(46.8 \%)$ & $61(43.0 \%)$ & 0.834 \\
Females (n, \%) & $83(53.2 \%)$ & $81(57.0 \%)$ & 0.987 \\
Family history (n, \%) & $39(25.0 \%)$ & $37(26.1 \%)$ & 0.351 \\
Onset (years, median \pm SD) & $45.47 \pm 12.72$ & $45.44 \pm 12.48$ & \\
Morning stiffness (n, \%) & & & \\
$\quad 0$ & $29(18.6 \%)$ & $31(21.8 \%)$ & 0.696 \\
$\quad<1$ hour & $93(59.6 \%)$ & $74(52.1 \%)$ & 0.846 \\
$>1$ hour & $34(21.8 \%)$ & $37(26.1 \%)$ & 0.253 \\
Deformities (n, \%) & $57(36.5 \%)$ & $55(38.7 \%)$ & 0.690 \\
ESR (median \pm SD) & $34.15 \pm 21.92$ & $33.65 \pm 21.90$ & 0.091 \\
Positive CRP (n, \%) & $91(58.3 \%)$ & $113(79.6 \%)$ & 0.568 \\
Positive RF (n, \%) & $127(81.4 \%)$ & $8.08 \pm 5.66$ & 0.808 \\
Tender joints (median \pm SD) & $9.22 \pm 5.99$ & $10.05 \pm 5.42$ & \\
Swollen joints (median \pm SD) & $10.42 \pm 5.66$ & $4.38 \pm 1.66$ & \\
DAS (median \pm SD) & $4.33 \pm 1.57$ & & \\
\hline
\end{tabular}

RF: rheumatoid factor; CRP: C-reactive protein; DAS: disease activity score in 28 joints. Statistical analyses were carried out with the $t$-test and chi-squared test.

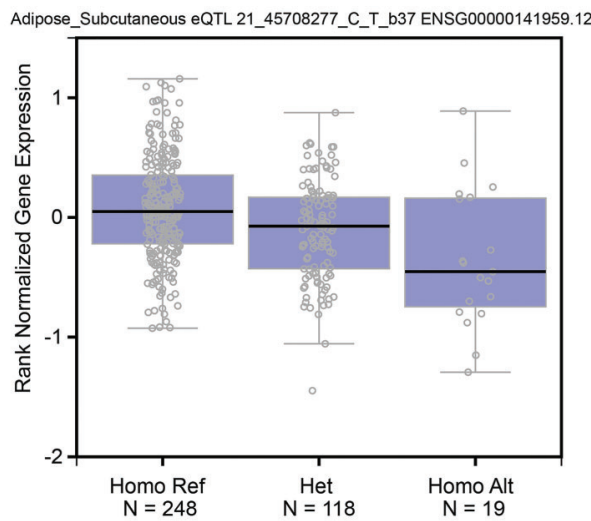

Figure 1. Proteins interacting with autoimmune regulator (AIRE). Homo ref: CC; Het: CT; Homo Alt: TT.

AIRE plays a functional role in thymocyte education and negative selection by controlling the thymus expression of peripheral antigens $(5,19)$. Dysfunction of the AIRE gene could lead to autoimmune polyendocrinopathycandidiasis-ectodermal dystrophy $(20,21)$. The association between several SNPs (rs2075876, rs760426, rs1800250, rs2776377, rs1055311, rs933150, rs1003854, rs2256817, rs374696, rs1078480) of the AIRE gene and RA risk was studied before, and a recent meta-analysis (22) proved that rs2075876 and rs760426 are significantly associated with an increased risk of RA. After genotype-tissue expression

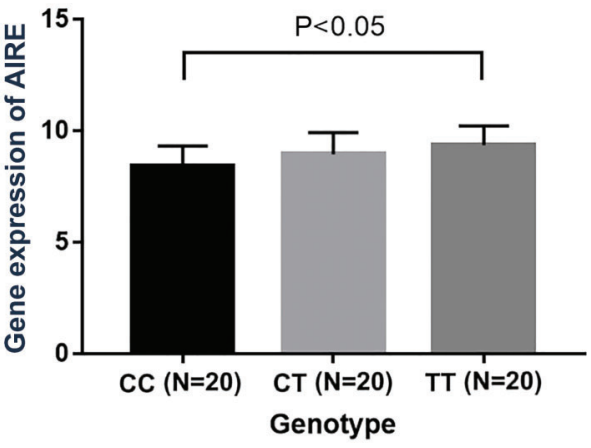

Figure 2. Expression levels of autoimmune regulator (AIRE). Data are reported as arbitrary units. $\mathrm{P}<0.05$ ( $t$-test).

analysis indicated that TT genotype of rs878081 polymorphism significantly decreased the AIRE expression, many researchers focused on the association between AIRE rs878081 polymorphism and RA risk. Garcia et al. (11) showed that the minor allele of rs878081 was significantly more frequent in RA patients than in controls from Spain, which was in line with our findings. However, two studies $(12,13)$ from West and North China, showed no evidence of association between rs878081 and RA risk. Such discrepancies could be attributed to four reasons. First, genetic heterogeneity may exist among populations and living environments, but RA results from the intricate interactions between various susceptibility genes and 
environmental factors. The effects of some genetic variants may vary across different populations and environments (1). Second, the study designs were different. The Spanish study (11) included fewer females in the RA group than the two Chinese studies $(12,13)$. Moreover, cases in the West China study (13) were considerably younger than cases in the North China study (mean age=43.5 vs 53.9 years). Genetic factors are often stronger in younger cases, and menopause status is an influential factor (23). Third, clinical heterogeneity may exist among studies. Fourth, since the sample sizes of some studies were too small to draw a convincing conclusion, the results may be false-positives or false-negatives. Nevertheless, a meta-analysis including this SNP is warranted to resolve inconsistence and evaluate the role of this SNP in the risk of RA.

Stratification analyses showed that the risk of RA conferred by the rs878081 polymorphism of the AIRE gene remained significant in the non-smoking subgroup, which was because susceptible individuals were likely to be exposed to risk factors to some extent. In addition, the genotype distribution of rs878081 polymorphism in relation to demographic, clinical, and laboratory data was analyzed. Individuals with TT genotype had more tender joints. However, given the decreased sample sizes in the stratification analyses and the limited power, the results should be interpreted with caution. Nevertheless, our findings still provide evidence for a possible interaction between the SNP and some RA risk factors.

Our results indicated that the AIRE rs878081 polymorphism increased the risk of RA in a Chinese population. According to dbSNP database, rs 878081 polymorphism will cause synonymous mutation when the nucleotide changes from $C$ to $T$. Then, we investigated the mRNA levels of different genotypes of rs878081 polymorphism in the Genotype-Tissue Expression Portal (17). The TT genotype decreased the AIRE mRNA levels compare to CC genotype in the adipose-subcutaneous. Considering that our clinical specimen was whole blood, we extracted mRNA from blood sample and conducted qPCR to determine the levels of AIRE. Similar results were observed in the patients' serum. Above all, the proportion of TT genotype increased in the RA group compared to the normal group. TT genotype is more likely to cause the down-regulation of AIRE compared to CC or CT genotypes. We hypothesized that AIRE rs878081 polymorphism con-

\section{References}

1. Silman AJ, Pearson JE. Epidemiology and genetics of rheumatoid arthritis. Arthritis Res 2002; 4 Suppl 3: S265S272, doi: 10.1186/ar578.

2. Myasoedova E, Davis JM 3rd, Crowson CS, Gabriel SE. Epidemiology of rheumatoid arthritis: rheumatoid arthritis and mortality. Curr Rheumatol Rep 2010; 12: 379-385, doi: 10.1007/s11926-010-0117-y. ferred susceptibility to RA by altering the expression levels of AIRE.

The association between the AIRE rs878081 polymorphism and risk of other autoimmune diseases was examined before (6,24-26). Ferrera et al. (24) reported no significant association of this SNP with risk of systemic sclerosis in an Italian population. No significant association was found between rs878081 polymorphism and Grave's disease (6), Addison's disease (26), or type 1 diabetes (25). However, some studies demonstrated that the ARIE rs878081 polymorphism conferred susceptibility to RA. The above differences among studies may be explained by the disease-dependent functionality of rs878081 polymorphism and should be confirmed by further studies.

This case-control study has several potential limitations that merit careful consideration. First, the patients and controls recruited from hospitals may not be representative of the general population. Nonetheless, the genotype distribution of the controls was in HWE. Second, because of the limited sample size, a single case-control study may be insufficient to fully uncover the relationship between the AIRE rs878081 polymorphism and susceptibility to RA. Thus, our findings should be confirmed by larger numbers of subjects. Third, we did not obtain detailed information about RA severity and response to treatment, which restricted our analyses. Fourth, the risk of RA cannot be attributed to a single AIRE gene SNP, but should be interpreted by considering other AIRE SNPs, other genes, and some environmental factors. Fifth, the underlying mechanisms of this SNP in RA were not investigated. Finally, the true significance of the association between this SNP and RA risk should be validated by further studies in different populations.

In conclusion, our study provided strong evidence that the rs878081 polymorphism of the AIRE gene may contribute to RA risk. However, this finding was obtained with a limited sample size representing a preliminary conclusion and should be confirmed by multicenter case-control studies with diverse ethnic populations.

\section{Acknowledgments}

This study was supported in part by National Natural Science Foundation of China (81702179).
3. Radovits BJ, Fransen J, Al Shamma S, Eijsbouts AM, van Riel PL, Laan RF. Excess mortality emerges after 10 years in an inception cohort of early rheumatoid arthritis. Arthritis Care Res (Hoboken) 2010; 62: 362-370, doi: 10.1002/ acr.20105.

4. Firestein GS. Evolving concepts of rheumatoid arthritis. Nature 2003; 423: 356-361, doi: 10.1038/nature01661. 
5. Anderson MS, Venanzi ES, Klein L, Chen Z, Berzins SP, Turley SJ, et al. Projection of an immunological self-shadow within the thymus by the aire protein. Science 2002; 298: 1395-1401, doi: 10.1126/science.1075958.

6. Colobran R, Gimenez-Barcons M, Marin-Sanchez A, Porta-Pardo E, Pujol-Borrell R. AIRE genetic variants and predisposition to polygenic autoimmune disease: The case of Graves' disease and a systematic literature review. Hum Immunol 2016; 77: 643-651, doi: 10.1016/j.humimm.2016. 06.002.

7. Cosway E, Anderson G, Garside P, Prendergast C. The thymus and rheumatology: should we care? Curr Opin Rheumatol 2016; 28: 189-195, doi: 10.1097/BOR.000000 0000000251.

8. Starr TK, Jameson SC, Hogquist KA. Positive and negative selection of T cells. Annu Rev Immunol 2003; 21: 139-176, doi: 10.1146/annurev.immunol.21.120601.141107.

9. Mellado M, Martinez-Munoz L, Cascio G, Lucas P, Pablos $\mathrm{JL}$, Rodriguez-Frade JM. T Cell Migration in Rheumatoid Arthritis. Front Immunol 2015; 6: 384, doi: 10.3389/fimmu. 2015.00384.

10. Terao C, Yamada R, Ohmura K, Takahashi M, Kawaguchi T, Kochi Y, et al. The human AIRE gene at chromosome 21q22 is a genetic determinant for the predisposition to rheumatoid arthritis in Japanese population. Hum Mol Genet 2011; 20: 2680-2685, doi: 10.1093/hmg/ddr161.

11. Garcia-Lozano JR, Torres-Agrela B, Montes-Cano MA, Ortiz-Fernandez L, Conde-Jaldon M, Teruel M, et al. Association of the AIRE gene with susceptibility to rheumatoid arthritis in a European population: a case control study. Arthritis Res Ther 2013; 15: R11, doi: 10.1186/ar4141.

12. Feng ZJ, Zhang SL, Wen HF, Liang Y. Association of rs2075876 polymorphism of AIRE gene with rheumatoid arthritis risk. Hum Immunol 2015; 76: 281-285, doi: 10.1016/ j.humimm.2015.01.026

13. Li X, Li T, Chen M, Chai $\mathrm{Y}$. Association of AIRE gene polymorphisms with susceptibility to rheumatoid arthritis among ethnic Han Chinese from Shaanxi. Chin J Med Genet 2016; 33: 373-377.

14. Aletaha D, Neogi T, Silman AJ, Funovits J, Felson DT, Bingham CO, 3rd, et al. 2010 Rheumatoid arthritis classification criteria: an American College of Rheumatology/ European League Against Rheumatism collaborative initiative. Arthritis Rheum 2010; 62: 2569-2581, doi: 10.1002/ art.27584

15. Prevoo ML, van 't Hof MA, Kuper HH, van Leeuwen MA, van de Putte LB, van Riel PL. Modified disease activity scores that include twenty-eight-joint counts. Development and validation in a prospective longitudinal study of patients with rheumatoid arthritis. Arthritis Rheum 1995; 38: 44-48, doi: 10.1002/art.1780380107

16. Gu H, Qiu W, Wan Y, Ding G, Tang W, Liu C, et al. Variant allele of CHEK2 is associated with a decreased risk of esophageal cancer lymph node metastasis in a Chinese population. Mol Biol Rep 2012; 39: 5977-5984, doi: 10.1007/ s11033-011-1410-1.

17. Gong J, Mei S, Liu C, Xiang Y, Ye Y, Zhang Z, et al. PancanQTL: systematic identification of cis-eQTLs and trans-eQTLs in 33 cancer types. Nucleic Acids Res 2018; 46: D971-D976, doi: 10.1093/nar/gkx861.

18. Hedges LV, Pigott TD. The power of statistical tests in metaanalysis. Psychol Methods 2001; 6: 203-217, doi: 10.1037/ 1082-989X.6.3.203.

19. Fierabracci A. Recent insights into the role and molecular mechanisms of the autoimmune regulator (AIRE) gene in autoimmunity. Autoimmun Rev 2011; 10: 137-143, doi: 10.1016/j.autrev.2010.08.019.

20. Buzi F, Badolato R, Mazza C, Giliani S, Notarangelo LD, Radetti G, et al. Autoimmune polyendocrinopathy-candidiasis-ectodermal dystrophy syndrome: time to review diagnostic criteria? J Clin Endocrinol Metab 2003; 88: 31463148, doi: 10.1210/jc.2002-021495.

21. Nagamine K, Peterson P, Scott HS, Kudoh J, Minoshima S, Heino M, et al. Positional cloning of the APECED gene. Nat Genet 1997; 17: 393-398, doi: 10.1038/ng1297-393.

22. Berczi B, Gerencser G, Farkas N, Hegyi P, Veres G, Bajor J, et al. Association between AIRE gene polymorphism and rheumatoid arthritis: a systematic review and meta-analysis of case-control studies. Sci Rep 2017; 7: 14096, doi: 10.1038/ s41598-017-14375-z.

23. Alpízar-Rodriguez D, Pluchino N, Canny G, Gabay C, Finckh A. The role of female hormonal factors in the development of rheumatoid arthritis. Rheumatology (Oxford) 2017; 56: 1254-1263, doi: 10.1093/rheumatology/kew318.

24. Ferrera F, Rizzi M, Sprecacenere B, Balestra P, Sessarego $M$, Di Carlo A, et al. AIRE gene polymorphisms in systemic sclerosis associated with autoimmune thyroiditis. Clin Immunol 2007; 122: 13-17, doi: 10.1016/j.clim.2006.09.013.

25. Turunen JA, Wessman M, Forsblom C, Kilpikari R, Parkkonen $\mathrm{M}$, Pontynen $\mathrm{N}$, et al. Association analysis of the AIRE and insulin genes in Finnish type 1 diabetic patients. Immunogenetics 2006; 58: 331-338, doi: 10.1007/ s00251-006-0088-3.

26. Boe Wolff AS, Oftedal B, Johansson S, Bruland O, Lovas K, Meager A, et al. AIRE variations in Addison's disease and autoimmune polyendocrine syndromes (APS): partial gene deletions contribute to APS I. Genes Immun 2008; 9: 130-136. 